\title{
Students' Perception of Peer Review in an EFL Classroom
}

\author{
Liliya Harutyunyan ${ }^{1} \&$ María Fernanda Poveda ${ }^{1}$ \\ ${ }^{1}$ Pontificia Universidad Católica del Ecuador \\ Correspondence: Liliya Harutyunyan, Luis Cordero E 9-39 y 6 de Diciembre, ed. San Francisco, dep.72, Quito, \\ 170524, Ecuador. Tel: 593-987-000-118. E-mail: lharutyunyan@puce.edu.ec; liliok_18@hotmail.com
}

Received: February 1, 2018 Accepted: March 27, 2018 Online Published: March 29, 2018

doi: 10.5539/elt.v11n4p138 URL: http://doi.org/10.5539/elt.v11n4p138

\begin{abstract}
Even though there is plenty of published information about the advantages of peer review, little can be found on what the beneficiaries (i.e. the students) feel about this method and what they might expect from it. In this paper, we present an analysis of the perceptions of 44 students at one of the largest universities in Ecuador, who had just undertaken a course in academic writing which used peer revision as the main tool for improving final essay compositions. The results show that participants of the groups who followed a peer revision approach do believe that they benefited from this method. This conclusion was reached after analysing students' answers to a questionnaire which comprised closed option (multiple choice) questions as well as open-ended responses on the same three aspects pertaining to the impact of peer review: critical thinking, collaborative work and composition quality. This research is based on Vygotsky's socio-cultural approach; it also supports and broadens previous investigations on this topic giving a more detailed and deep-rooted perspective, as participants who have used this methodology comment on its benefits and/or flaws.
\end{abstract}

Keywords: peer review, students' perception, academic writing

\section{Introduction}

The present study is based on Vygotsky's socio-cultural approach which emphasizes the importance of social interactions in order to develop cognition (Vygotsky, 1978). Under this approach the students in an EFL class should be seen as a community in which interaction among peers is essential to help individuals construct meaning. In such a context, feedback is not exclusively provided by the teacher, but students also undertake an active role to make revisions, provide comments, participate in dialogues and discuss experiences within the socio-cultural paradigm (Evans, 2013). The introduction of PR under the constructivist approach to learning not only helps students improve the quality of their final draft but also provides a source of L2 learning (Shehadeh, 2011). The adoption of this assessment approach becomes imperative in EFL classes since many institutions have adopted the Common European Framework of Reference (CEFR) as a tool for establishing guidelines in terms of the objectives and competences that a student of English must acquire upon finishing their university education. The CEFR places students at the center of the learning process. Therefore, adjustments to methodology and assessment adjustments will need to be made in order to reach course objectives (Planas Lladó et al., 2013). Peer review is a tool that places the student at the center of his or her learning process. Indeed, peer review has been widely used in higher education to help students learn more effectively and more thoroughly analyse their own and their peers' inaccuracies in academic written texts. Thus, peer review should not be considered an instrument of assessment of learning but rather assessment for learning (Boud \& Molloy, 2013).

It is widely acknowledged that successful composition of high quality academic texts at university level is closely linked to educational and professional success, as this skill is a tool both for studies at university level, and competent professional operation throughout entire careers after graduating from university (Crossman \& Kite, 2012). At this level, the writing process should not be seen as a standardized system of communication but rather a learning tool that allows students to develop their reflective capability and favour collaborative work in order to prepare them for the rigours of the professional world, since 'PR can encourage students to become more sophisticated thinkers and writers.' (Baker, 2016). Hence, the peer review method is a strategy used to help students progress in their writing skill, while simultaneously advancing in collaborative work and critical thinking tasks. Therefore, training students in peer review will provide them with skills for their professional development and lifelong learning. In fact, researchers have demonstrated that students who have developed the skills of peer review during their academic training are able to accept criticism from their colleagues or superiors 
and learn to judge more fairly the quality of a peer's work (Planas Lladó et al., 2013).

There is abundant information about the Peer Review methodology (PR) and its advantages and drawbacks, as much has been published, discussed, and debated on this topic. Moreover, it is a tool that is widely incorporated in language classrooms, as well as in foreign language learning, and EFL teaching has been greatly impacted by it (Hu, 2005; Hanrahan \& Isaacs, 2010; Nicol \& Macfarlane-Dick, 2006; Topping, 2009). In such classrooms, the traditional role of the instructor to provide feedback is often carried out by peers, who thereby become independent learners, improve their own and their peers' texts, and are bestowed with multiple benefits (Coté, 2014; Yang, 2011; Gielen \& De Wever, 2015; Planas et al., 2014). Researchers and professors are strongly convinced that the PR method, when applied as a strategy in a writing classroom, is practical for clarifying learning objectives, criteria, standards and other external reference points. It also helps self-regulation of learning, provides students with high-quality information about their learning processes, and benefits student-student and student-teacher communication, thus guiding teachers in the task of seeking more appropriate ways of teaching, decreasing the gap between current and desirable results, as well as increasing students' motivation and self-esteem (Nicol \& Macfarlane-Dick, 2006). Despite all the aforementioned benefits, some drawbacks have been outlined in previous studies. First of all, students may feel they are not qualified to give appropriate feedback. This issue may be even more evident when a low-achieving student is asked to work with a high achiever. Topping (2009) also mentions that the benefits of PR could be invalidated due to the forces of social interaction such as: friendship bonds, enmity, and conformity, among others. However, Gielen and De Wever (2015) acknowledge the fact that students need to develop skills in order to perform their PR role appropriately. They conclude in their study that a practical instructional intervention on the feedback process increases the potential impact of peer assessment and boosts students' learning in higher education. Moreover, explicit instruction for students on the benefits of peer review will positively impact their motivation and level of responsibility, as well as engagement in the task (Topping, 2009).

Nevertheless, students' views are not particularly considered by authors, which would be imperative since learners are assumed to be the main beneficiaries of this process. Despite this, some research investigating second language learners' reactions to collaborative writing claim positive effects on the students in terms of co-operation, critical thinking and composition quality itself (Fernandez Dobao \& Blum, 2012; Riazantseva, 2012; Shehadeh, 2011).

This study analyses the perception of three key elements of peer review and their effect and importance from the students' point of view. Critical thinking is fundamental within this process, as learners need to be able to analyze their peers' writing, not just at a linguistic level, but more importantly at a communicative level, and ideally be able to go back to their own writing and make changes stemming from this. The ability to give constructive feedback rather than merely criticizing classmates and receiving critique from peers without feeling offended or misjudged by others are signs of optimal participation in collaborative work, which is integral to any future professional life. Likewise, it is anticipated that PR will lead to improvements in writing throughout the entire process, a fact that cannot be overlooked by undergraduates.

\subsection{Critical Thinking}

Nowadays, in addition to covering a specific field of knowledge, universities aim to form students with specific competences such as cognitive competences including critical thinking, critical analysis of information, problem solving, and inventing or creating new things. In addition, meta-cognitive competencies such as self-reflection and self-evaluation are prioritized (Birenbarum, 1996). One tool for working towards these objectives is peer review which contributes to the development of critical thinking in students (Hanrahan \& Isaacs, 2010; Douchy, et al., 1999; Cheng, 2009; Kosheleva, 2010). Directed peer review may improve written ability together with the corresponding development of essential skills such as critical thinking. (Crossman \& Kite, 2012; Kim, 2015; Hammond, 1999)

\subsection{Collaborative Work}

According to the socio-cultural theory of mind, learning a second language can only occur through interaction. Thus, learning a language is a socially situated activity (Vygotsky, 1978). For this reason, Hodges (2002) goes so far as to claim that students should learn to write collaboratively with teachers and peers before they become autonomous writers (Hodges, 2002). Fernandez and Dabao (2013) concluded in their study that collaboration, solution of language-related problems, and even the construction of new knowledge are greatly advanced through collaborative writing.

Furthermore, to achieve optimum outcomes in peer review methods, students need to communicate and share ideas, mastering their ability to confidently provide and objectively receive constructive feedback. As such, 
collaborative work is an essential element within this process. Peer review is beneficial for students: it improves motivation, socialization and communication skills (Crossman \& Kite, 2012; Hanrahan \& Isaacs, 2010). Peer review activities are not only important at the brainstorming level, but throughout the whole writing process. (Fernandez Dobao \& Blum, 2012) Collaborative writing activities expand students' academic writing competences and motivate more independent learning (Wigglesworth \& Storch, 2012). Another benefit of this process is that peers can mutually ensure that no kind of inadvertent plagiarism is used in their writing (Thomas, 2014). Consequently, well-structured and correctly-scaffolded peer review tasks can help students to develop collaborative skills in order to work jointly on a common goal, increase creativity, autonomy and motivation, and even promote deeper learning.

In this study, the term collaborative work is used to refer to the ability of all members of the group to give and receive constructive feedback through a dialogue and improve each individual's essay, rather than writing one joint essay each group.

\subsection{Composition Quality}

'There is substantial evidence that peer assessment can result in improvements in the effectiveness and quality of learning, which are at least as good as gains from teacher assessment, especially in relation to writing.' (Topping, 2009) During peer review practice, students evaluate the products or performance of equal-status others, aiming toward better-quality writing. (Crossman \& Kite, 2012) Despite some drawbacks, the peer review practice has been proven to have a positive effect on students' quality of texts, which is the very essence of the peer review method (Deni \& Zainal, 2011). Text quality is positively affected by collaborative dialogue (Shehadeh, 2011; Martin \& Provost, 2014; Baker, 2016; Fernandez Dobao \& Blum, 2012; Wigglesworth \& Storch, 2012). Several studies have emphasized the positive influence that peer review has on the quality of production. In their study, Kuikken and Vedder (2002) demonstrate that collaborative dialogues have a positive effect on the text quality in L2. These researchers notice that students involved in this practice gain more language awareness and, as consequence, are able to deepen their understanding of lexical patterns and grammar rules. They also state that dialogues with peers may consolidate students' previous language knowledge. Storch (2005) concludes that when students work in pairs their texts are shorter but more complex than when students work individually. She concludes that pairs seem to fulfil the task more competently. Also, Shehadeh (2011) reports that collaborative writing has a positive impact on text production. His statistical analysis reveals that the areas of content, organization and vocabulary receive greater benefit than the areas of mechanics and grammar. Finally, Crossman and Kite (2012) report that once students had handed in their final draft, a clear improvement was noticeable in the following areas: support, audience focus, writing conventions, and organization. Provided that teachers lead their students through the entire process, peer review can certainly improve learners' writing quality (Hu, 2005). Throughout the peer review process the quality of students' writing gradually improves (Cheng, 2009).

Even though tutors often express doubts about learners' abilities in peer-assessment, students generally show reasonable insight into their peers' achievements (Evans, 2013). Furthermore, students declare that this method helps them to think and learn more, (Douchy et al., 1999) and involving them in this process is a very positive and well-founded practice, which also assesses progress in writing skill (Douchy et al., 1999; Topping, 2009) Peer-assessment allows students to get involved in a challenging activity and to widen their understanding of the subject (Planas et al., 2013) Overall, students showed a positive reaction towards collaborative prewriting activities, which helped them to better understand the task, its audience and purpose (Neumann \& McDonough, 2015). Some learners are forced to reanalyse what they have previously written after it is reviewed by their partners (Coté, 2014). Students registered positive feedback on all six processes for externalizing knowledge: modelling, coaching, scaffolding, articulation, reflection and exploration (Yang, 2011).

\subsection{Research Questions}

The authors' response to the aforementioned points, was to frame four key questions for the current paper:

- After undergoing the peer review process, do students agree that it helped them to improve their collaborative work competence?

- Is peer review regarded by students to be a tool fomenting critical thinking skills?

- Do students perceive the peer review method as useful in the development of academic writing skills?

- Do learners recognise this method to be of equal importance as professors and researchers do? 


\section{Method}

\subsection{Participants}

The participants in this investigation were 68 students ( 32 men and 36 women) studying English at Pontifical Catholic University of Ecuador (PUCE), located in Quito, during 2 semesters of 2016-2017 academic year. The groups in each semester were divided randomly into two groups with the same number of students in each: control (34 students) and experimental groups (34 students), where PR was worked out with experimental groups only. Control groups completed all the tasks without undergoing PR process. They had reached levels 7 and 8 of the programme (a B2 level according to the Common European Framework of Reference for Languages) and were registered in 4 different groups (level 8-10 students in each). (Students reach these levels after passing all previous levels at the university or after getting a satisfactory score for these levels after a standard English ubication test). Additionally, the results of 10 participants (academic and administrative personnel of the same university) of an extensive course (4 men and 6 women), which was designed similarly, were analysed. This study examined the perception of total 44 participants; the overall sample is of 78 partakers.

\subsection{Course}

Development of Academic Writing (AW) skills through the PR tool was taught in parallel with the main subject (an English language course) offered by the university twice a semester over approximately 2 months. Generally on this main course, the four language skills are developed: listening, reading, speaking and writing. In addition, grammar and vocabulary are introduced for level B2 using a Cambridge University Press coursebook called Empower (Doff et al., 2016). Furthermore, in order to allow students to write an argumentative essay, a documentary is presented about a controversial issue portraying human rights issues, unequal living- and working conditions, industrial pollution, diseases that result from pollution, or environmental damage caused by the textile industry, among other topics. After watching the documentary, reading articles, reflecting on the topic and participating in classroom discussion, students were guided through worksheets and peer review to write an argumentative essay emphatically expressing their point of view on the subject. The main goal of the peer review sheets was not to evaluate their peers, but to provide students with constructive feedback in order to help their classmates achieve more favourable outcomes in their final written essay. Students were told to do so at the beginning of the course, an instruction which was repeated several times by the professor over the duration of the course and before each peer review worksheet was handed in.

\subsection{Instruments}

\subsubsection{Academic Writing Guide}

A 100+ page guide for academic writing and peer review created by this project's professor-investigators was given to students to introduce the peer review tool and train them in academic argumentative essay writing. This booklet is completely in English and includes a description of academic writing at university level and peer review as a tool for developing critical thinking, collaborative work and improving the quality of essays in English, as well as some structure and vocabulary exercises to train learners in this process. The guide also outlines four different types of essay (descriptive, expository, argumentative and application) although time limitations meant only the argumentative essay was actively worked through on this occasion.

\subsubsection{Academic Writing Worksheets}

These worksheets were designed by the professor-investigators and included: (1) prewriting activities (listing), divided into pros, cons and other relevant information, followed by (2) a thesis statement for the argumentative essay, (3) an outline worksheet, (4) introduction and conclusion, (5) first draft, (6) second draft, and (7) final version.

\subsubsection{Peer Review Worksheets}

The peer review worksheets on each activity (thesis statement, outline, introduction, conclusion, first draft, second draft) were given out. These worksheets are specifically task-oriented, asking peer reviewers for written responses on both the worksheet and the copy of their author's essay.

\subsubsection{Questionnaires}

Three questionnaires were generated asking for students' opinions of the PR course and its effects. As anonymity is claimed to be a more objective tool (Coté, 2014), it was decided to apply it also in the questionnaire and final course feedback, and students handed in their papers without names on them. Each questionnaire consisted of 10 questions, with the students first answering a closed question (multiple choice) and then expanding their response in more detail and explaining it (See ANNEXES for details). 
There are 4 closed answers as options to choose from: a. totally agree, b. somewhat agree, c. somewhat disagree, d. disagree. After choosing one of these options the students had to justify their response.

\subsubsection{Peer Review Process}

This empirical-comparative study was carried out with 4 groups ( 2 experimental and 2 control groups), each undergoing the same process including thesis statement, outline, introduction, conclusion, first draft, and second draft writing activities. However, only the experimental groups used the PR tool and filled in the worksheets. In each experimental class after explaining the PR process which would be followed, the professor asked students to get into pairs. The students were allowed to choose their partner, and most pairing decisions were based on friendship or affinity. All students were accompanied by the same partner throughout, i.e. reviewed the same author's writings, and were reviewed by the same person whose work they were reviewing.

\subsubsection{Evaluation of Texts and Drafts}

This process involved an evaluation system for the final paper which was designed and presented by professor-investigators based on an analytical scale from Jacobs (1981) and for the first and second draft based on the Common European Framework of Reference for Languages (CEFR). The rubric forms considered: (1) content relevance and adequacy, (2) compositional organization, (3) cohesion, (4) appropriacy of vocabulary for purpose, (5) language use, and (6) mechanics. Mistakes found in writing samples were corrected and coded by the researchers and research assistants in order to analyse any differences between the prewriting activities and the first draft, as well as between the first draft and the final outcome of each student. These coded errors were grouped into the following categories: grammar, vocabulary and mechanics on one hand, and communicative competence on the other.

\subsubsection{Others}

(1) Observations were carried out by professors and two linguistics students who formed part of this project. In addition (2) feedback was given to the professor, and (3) about the course. Students were asked to write an argumentative essay (500-700 words) with the following structure: first paragraph - introduction, second paragraph - body paragraph 1 (argument), third -body paragraph 2 (counterargument), and fourth - conclusion. The structure of each paragraph was given and explained (5-8 sentences each). The individual set of papers for project for each student resulted in 6 writing and pre-writing activities and 5 activities on Peer Review.

\section{Results}

Overall for the report and its interpretation 1320 numerical points are considered in this research paper (440 for collaborative learning, 440 for critical thinking, and 440 for quality of the argumentative essay composition). Below, the points for response are listed with four options - A, B, C, and D - where A means totally agree, Bsomewhat agree, C-somewhat disagree, and D- disagree. After each of these, the corresponding open-ended answers are reproduced.

\subsection{Collaborative Learning}

Collaborative learning is one of the essential aspects to be examined in the studies of PR tool (Shehadeh, 2011; Wigglesworth \& Storch, 2012), as it is not straightforward to work in pairs or groups, to agree on various aspects, nor to give and receive feedback. This research investigation uncovered the following.

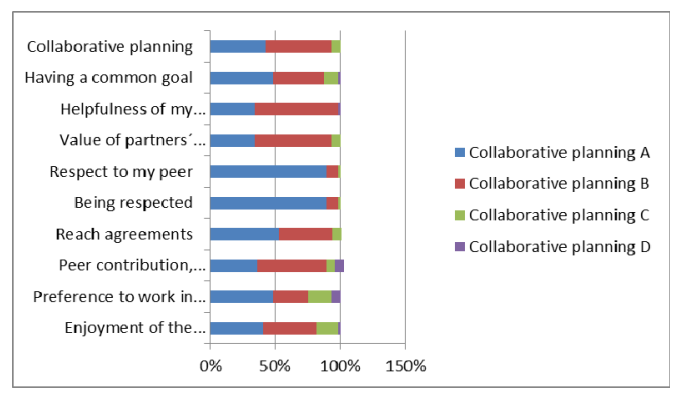

Collaborative learning indicators show a very high degree of acceptance and a positive attitude to PR, with $80 \%$ of students reporting a preference for working in groups and having enjoyed the process. Fewer than $20 \%$ of students expressed the opinion that collaborative learning was of little use, while almost $90 \%$ claimed they respected their peers and showed their classmates great respect, which is probably the reason why the great 
majority of them declared that they would rather work in pairs or small groups than alone.

As a suggestion for further research in this area, qualitative follow up work could be undertaken with the $20 \%$ of students whose responses were less positive, and may reveal differences in learning styles.)

\begin{tabular}{lllll} 
Collaborative planning & \multicolumn{4}{c}{} \\
\cline { 2 - 5 } & $\mathrm{A}$ & $\mathrm{B}$ & $\mathrm{C}$ & $\mathrm{D}$ \\
Collaborative planning & 19 & 22 & 3 & 0 \\
Having a common goal & 21 & 17 & 5 & 1 \\
Helpfulness of my feedback & 15 & 28 & 0 & 1 \\
Value of partners'feedback & 15 & 26 & 3 & 0 \\
Respect to my peer & 39 & 4 & 1 & 0 \\
Being respected & 39 & 4 & 1 & 0 \\
Reach agreements & 23 & 18 & 3 & 0 \\
Peer contribution, understand AW & 16 & 23 & 3 & 2 \\
Preference to work in pairs & 21 & 12 & 8 & 3 \\
Enjoyment of the process & 18 & 18 & 7 & 1 \\
\hline
\end{tabular}

(1). Students' comments: a. It (planning outlines for future written assignments together) has been a real help in improving my writing. b. It helped me to discover a better way to write the final essay. c. The interaction with my partner was useful in refining the outcome.

(2). Students' comments: a. Sometimes we do, but at other times we do not. b. I think working with a partner was really important because through this process we were able to see how other people may feel about our work, and may even help us to improve the work. c. Even though working with a partner kind of helps, we had such different backgrounds that it was hard to provide feedback to each other.

(3). Students' comments: a. It was hard to help because of our lack of experience in peer revision. b. I learned to give useful feedback. c. No, because my partner's knowledge of language is better than mine.

(4). Students' comments: a. Some of them were, but others were not as important. b. In structure, unity and cohesion. c. Definitely. Sometimes when somebody else reads your work, they notice what you cannot see.

(5). Students' comments: a. Yes, respect is essential in any social process. b. Most of the time. c. Suggestions were presented clearly and with great respect.

(6 Students' comments: a. I tried to be objective and respectful. b. I always had respect in mind while peer reviewing. c. Always.

(7). Students' comments: a. As they just provided suggestions, I made changes only if I considered them to be necessary. b. We don't always have to accept our partner's point of view. c. Peer review is an opportunity to exchange ideas and perceptions, where understanding each other's point of view is a must.

(8). Students' comments: a. Yes, because at the beginning of the process one may easily forget the tips and rules. b. Yes, I understood something that hadn't been clear. c. Yes, my partner helped me to see my work differently.

(9). Students' comments: a. I like both ways of working. b. I would rather work alone. c. Working in groups is fun, but it is difficult to agree on some points.

(10). Students' comments: a. It was interesting because it gave me a chance to learn and help my partner in the process. b. Sometimes it is hard to face criticism. c. Yes, it is rewarding both to review our peers' work and to be peer reviewed.

\subsection{Critical Thinking}

The development of critical thinking is also important during the PR process (Baker, 2016; Hu, 2005; Coté, 2014). 


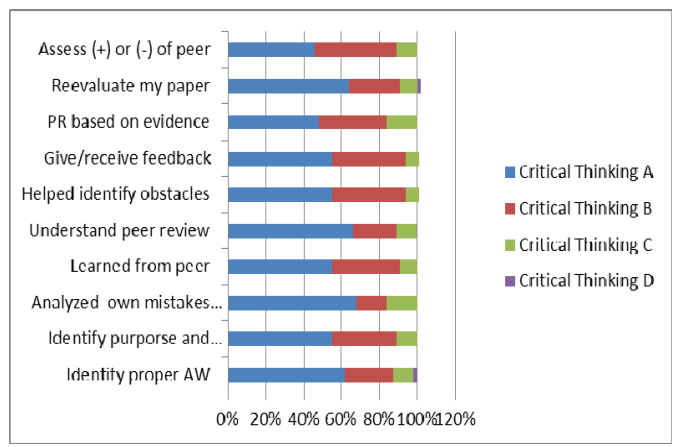

More than $75 \%$ of students responded positively to the vast majority of critical thinking indicators. While the ability to identify proper Academic Writing ranks slightly lower, students' comments reveal that progress is also being made in this area, and benefits will become more apparent over time. There were no totally negative answers (option D) in this category, just with respect to being able to identify a proper academic writing essay from one that is not. This possibly reflects the fact that students do not feel confident in their academic writing skills and ability to help others without an instructor's help. A large part of the group considers their peers worthy of this task and they took full advantage of peer review tool.

\begin{tabular}{lllll}
\hline Critical Thinking & & & & \\
\cline { 2 - 5 } Assess (+) or (-) of peer & $A$ & $B$ & $C$ & $D$ \\
Reevaluate my paper & 20 & 19 & 5 & 0 \\
PR based on evidence & 28 & 12 & 3 & 1 \\
Give/receive feedback & 21 & 16 & 7 & 0 \\
Helped identify obstacles & 24 & 17 & 3 & 0 \\
Understand peer review & 29 & 10 & 5 & 0 \\
Learned from peer & 29 & 10 & 5 & 0 \\
Analyzed own mistakes on peer's paper & 24 & 16 & 4 & 0 \\
Identify purporse and audience & 30 & 7 & 7 & 0 \\
Identify proper AW & 24 & 15 & 5 & 0 \\
\end{tabular}

(11). Students' comments: a. Yes, now I know how to do it properly. b. Sometimes, because each of us has their own forms of expression and only a teacher could really guide us. c. It was a hard task.

(12). Students' comments: a. Yes, with the teacher's help. b. Yes, because I had to revise some grammar and specific words in order to complete peer review. c. Yes, my partner's point of view helped me in this task.

(13). Students' comments: a. I think that I did, yes. b. There was not very much to correct. c. I think I encouraged my partner to write better.

(14). Students' comments: a. I was able to do so, but it was hard. b. Yes, I can. c. I think I still have limitations in doing so.

(15). Students' comments: a. Yes, definitely. b. Yes, and the final result was even better. c. Yes, and I saw the topic from a different perspective.

(16). Students' comments: a. Sometimes I did, some other times it was confusing. b. Yes, I consider it very useful. c. Yes, it helped us to see our previous mistakes.

(17). Students' comments: a. Yes, and it helped me to improve the final result. b. Yes, quite a bit. c. Yes, I learnt a lot.

(18). Students' comments: a. Yes. b. Kind of. c. Yes, because it is part of the process. 
(19). Students' comments: a. It is difficult. b. Not always. c. Yes, easily.

(20). Students' comments: a. Yes. b. After the course, I do agree with this statement. c. I am still in the process of developing this skill.3

\subsection{Quality of Composition}

Quality of composition is highly and beneficially affected in groups who undergo the Peer Review technique (Topping, 2009; Baker, 2016; Hu, 2005). 75\% of students either agreed or strongly agreed that all aspects of written language and content had been positively impacted during the PR process. Ideas and structure seem to have derived greatest benefit overall, with cohesiveness and progress in the 2nd draft achieving slightly lower but still overwhelmingly positive results.

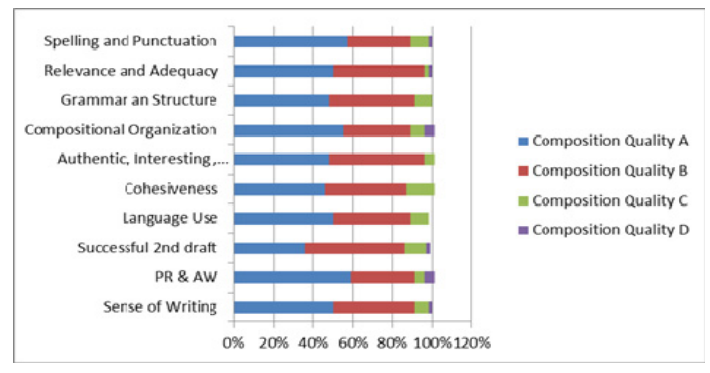

Students felt very confident in assisting their peers' written content as well as mistakes in structure and language use, but surprisingly felt less confident with writing mechanics. Interestingly, participants also showed self-reliance in changing content, cohesiveness and at the ideas level, too. This data may reflect the fact that academic writing was explained well, as well as the processes regarding how students were expected to help their peers, and the kind of comments they should accept in their follow-up work so as to achieve proper results in their academic essays. Notwithstanding, there are lower percentages of agreement in students accepting that their final draft made more sense than their first draft. Some of the group thought their compositional organization was not yet good enough, and some others were not sure if PR helped to improve their final outcome.

Composition Quality

Spelling and Punctuation

Relevance and Adequacy

Grammar and Structure

Compositional Organization

Authentic, Interesting , Engaging

Cohesiveness

Language Use

Successful 2nd draft

$P R \& A W$

Sense of Writing

\begin{tabular}{llll}
\hline$A$ & $B$ & $C$ & $D$ \\
25 & 14 & 4 & 1 \\
22 & 20 & 1 & 1 \\
21 & 19 & 4 & 0 \\
24 & 15 & 3 & 2 \\
21 & 21 & 2 & 0 \\
20 & 18 & 6 & 0 \\
22 & 17 & 5 & 0 \\
16 & 22 & 5 & 1 \\
26 & 14 & 2 & 2 \\
22 & 18 & 3 & 1 \\
\hline
\end{tabular}

(21). Students' comments: a. Yes. b. It is challenging for me. c. There is still a lot to learn.

(22). Students' comments: a. Yes, very much. b. Yes, I could. c. It is still difficult for me.

(23). Students' comments: a. Yes, but I have to make a huge effort to explain what I mean. b. Yes, I tried hard, and I think I fulfilled my expectations. c. Yes, I think so.

(24). Students' comments: a. It is confusing. b. I tried. c. I did my best. 
(25). Students' comments: a. Yes, but what I find interesting is probably not so for others. b. What I wrote was honest and interesting. c. Yes, I could achieve this.

(26). Students' comments: a. Yes, especially the last one. b. I think so. c. Sometimes.

(27). Students' comments: a. Yes, and when I can't think of the right word or a phrase, I look it up in a dictionary or I ask my teacher for help. b. Yes, most of the time. c. Yes, but sometimes I felt I needed to use a different kind of vocabulary.

(28). Students' comments: a. I hope so. b. I don't think so. c. Yes, I did.

(29). Students' comments: a. Definitely. I learnt a lot. b. Yes, the process and methodology were helpful. c. It gave me a chance to improve.

(30). Students' comments: a. I still have to improve. b. I did my best not to appear worse than I am in my partner's eyes. c. Yes, because PR provided a methodical process for writing.

\section{Discussion}

The results of this study are accounted for in terms of the social-constructivism view of learning in which one of the underlying premises is that classrooms must be seen as dynamic social systems. As discussed in the introduction, social interaction is essential to generate and consolidate knowledge (Vygotsky, 1978). In the case of L2 learning and teaching, "this means that learners first collaboratively construct knowledge as a joint activity, and then transform it into a mental one" (Shehadeh, 2011).

As can be seen from the results, the majority of students consider that planning their outlines for future writing assignments together is both useful and helpful for reaching more optimal outcomes at the end of the course. Another study shows that students perceive it as both a motivating and recommended methodology that facilitates the acquisition of learning at different levels (Planas et al., 2013) Furthermore, they think that it is easier to achieve better results if they work together. These results confirm Storch's (2005) findings. In her study 16 of the 18 students were positive about the experience. Similar results are also obtained in a different study in which $91.6 \%$ of students were generally positive of the peer review process. Students have indicated that they find the peer editing practice interesting, challenging and useful (Deni \& Zainal, 2011).

Additionally, learners feel that they help their partners to improve somewhat and they are also helped by their peers, as well as being highly respected by them, and showing their classmates great respect too. Also, participants almost always reached agreements with their partner, even though this was not a particularly easy task. Generally speaking, peer reviewers guided each other in order to improve all aspects of their essays. One study that confirms this perception states that the activity of reviewing their partner's written assignments had brought increased confidence and enhanced subject knowledge, as well as appreciation of the intricacies of assessing their own and peers' work (Planas Lladó et al., 2013). Notably, despite encountering some small-scale difficulties such as doubt and uncertainty during the process, pair and group work was stated as being preferable to working individually. Also, students did seem to enjoy the peer review process as much as the researchers had expected, even though there were still some individuals who expressed negativity towards this tool. It is also important to mention that all of the students who circled option (c) or (d) in this part of the questionnaire had experienced some kind of emotional disagreement with their peer in an out-of-class environment. Perhaps the results might have been even more positive if some students had worked with people they got along better with.

Regarding critical thinking, most students felt they were able to assess their partner's paper and give valuable comments on it, they also felt able to re-evaluate their own paper having followed the PR process. (Vickerman, 2009) also gets similar results. He demonstrates that students assessing their peers' work are engaged in a cognitively demanding activity that broadens their understanding of the subject matter. Although they did not feel very confident identifying their partner's writing obstacles, they did feel they were skilled in giving and receiving constructive feedback, but not convincing the author to change their mind. There was high degree of recognition for critical thinking having improved in the second draft. A large number of students professed to learn what this method is for, and a significant proportion of them accepted they had learnt from their partner's comments and suggestions on their own essay. Perhaps one of the most positive findings for the researchers was that participants referred back to their own mistakes while reading and assessing their partner's essay. Although learners were able to identify the purpose and the audience that the task required, it didn't appear to be easy to accomplish or address these appropriately. Another important point, which will be very useful in students' future careers as well as in language learning is the fact that the best part of the group was able to differentiate appropriate academic writing from that which is not properly written.

Learners' comments on their quality of their compositions reflected the following. A large number of them stated 
they could totally or almost completely improve on essay mechanics, or grammar and structure. In their research about students' perception, Planas and Lladó et al. (2013) reveal that students consider that peer assessment has made them think, learn more and be more structured than some tutor-based assessments. They regarded the content of their written production to be relevant and appropriate for academic writing. Just a few of them thought that the compositional organisation and format of their paper did not fulfil the requirements of academic writing. Furthermore, students found that the ideas that they had developed were interesting, authentic and engaging. Learners were doubtful about how cohesive their essays were. Interestingly, the language they used was seen to be varied and appropriate to the subject matter. However, they were not sure if they had met their partner's and teacher's expectations in their final version. A large number of students stated that the peer review process had favoured their ability to write. The majority of them considered that their writing now makes more sense after the course.

It should be mentioned that students were aware they would be evaluated on the quality of feedback given, which, on the other hand, would not affect the author's grade at all. This fact could be crucial for the final outcomes to be as good as expected. It was repeatedly explained that the reviewer's feedback would under no circumstance alter the author's evaluation, while the reviewer's score would be highly influenced by the type of comments given, and any changes that their feedback prompted in their peer's subsequent work.

Instructors need to know that many factors influence the students' perception about the process of peer review. First of all, acceptance of the classmate who they choose to work with, at the beginning of the process, but mostly during the course. Secondly, the tutor's approach is important. They should guide but not get so involved that students depend on the teacher's comments and feedback practically as much as their peer's judgement, so results do not become manipulated or subjective. Third, an extended and repeated explanation of the peer review process is crucial, as in the Ecuadorian environment this tool is scarcely used at school or even at university level And, finally, even though it was stated that a teacher's intervention is not something we would expect, their help is instrumental in case of disagreements about grammar, vocabulary or mechanics, or even to clarify students' confusion over content.

\section{Conclusion}

The majority of published material on the topic of PR is focused on considerably different aspects in comparison to this research paper, as emphasis is usually placed on the scholars' perspective on this topic, whose views centre on only one of the points included in this research initiative. Notwithstanding, this investigation was carried out to discover students' perceptions on collaborative learning, critical thinking and progress with composition quality. Thus, answering the questions of this study one by one, the following conclusions can be drawn:

After undergoing the peer review process, do students agree that it helped them to improve their collaborative work competence?

It is evident from this study that, overall, students regard the PR method as a useful strategy to improve their collaborative work skills in prewriting activities as well as during the process of academic writing, because they feel they and their partner have a common goal together. They also feel empowered because they believe their contributions are useful. Hence, they enjoyed the process because they respected others and felt respected themselves, even though they felt they would've needed more training to be able to prompt more fundamental change in their partners' writing.

Similar to another research paper (Fernandez Dobao \& Blum, 2012) the vast majority of students considered peer review a very helpful tool to learn more, to broaden vocabulary and consider structural and communicational mistakes.

Is peer review regarded by students to be a tool fomenting critical thinking skills?

Learners commonly expressed that they were perfectly able to make changes to their peers' mechanics, grammar, and vocabulary choices, as well as aspects of content and communication, even though they did not feel very confident about how beneficial this would be for their peers. One meaningful position worth a mention is that participants stated the PR process had helped them to re-evaluate their own paper and see it from a different perspective.

\section{Do students perceive the peer review method as useful in the development of academic writing skills?}

In the end, more than $70 \%$ of participants noted that PR had helped them in improving various aspects of their writing such as mechanics, grammar and structure, content, compositional organization and format, cohesiveness, creativity, and language use. More than half of the students considered that all the aforementioned aspects were 
highly influenced by the PR method.

\section{Do learners recognize this method to be of equal importance as professors and researchers do?}

The vast majority of students approved of this method, and no one expressed opinions against it. Nevertheless, the feedback was carried out immediately after the course. Given that the results of the outgoing students who took part in this course show a transformation in their writing ability (according to their final results assessed by the researchers), as well as the quality of their collaborative work and critical thinking skills (according to learners' self-evaluations), any future academic studies should focus on the long-term effects of PR within an academic writing course to reveal whether this strategy works only in the short-term, because, as is widely recognised, researchers' objectives pursue life-long changes in university students.

In the current study it has been proven in many ways, that students perceived peer review activities to actually help their progress in writing skills, and acknowledge that the end- result was greatly different in comparison to the first draft when PR was not used. Moreover, students considered the peer review method as a useful strategy for improving their collaborative work skills in pre-writing activities, as well as during the academic writing process. They also felt empowered because they noticed that their contributions were useful. Therefore, they enjoyed the process because they respected others and felt respected, even though they were aware that they would need more training to be able to do the job optimally. The vast majority of students consider peer review a very useful tool for learning more, expanding vocabulary and considering structural and communication errors. Indeed, they acknowledged that the end-result was extremely different in comparison to the first draft when PR was not used, as has also been shown in another study (Riazantseva, 2012).

This research is not without limitations. Perhaps if students' discussions had been recorded, we could have gained a clearer perspective on whether peer review does generate true collaborative work and development of critical thinking. Furthermore, if interviews had been conducted, we would have had a clearer vision of why certain students did not empathize with this pedagogical tool. Another limitation of this study could be the fact that the same task was carried out with all groups; another could be that the analyses were carried out on the same essay (from listing points to the final draft), so no other types of essay which might include other topics and lexical range have been taken into account.

Any future academic studies should focus on the long-term effects of PR within an academic writing course to reveal whether this strategy works only in the short-term, because, as is widely recognised, researchers' objectives pursue life-long changes in university students.

What distinguishes this piece of research is that, in contrast to previous studies which examined only one of the aspects described in this research, i.e. either collaborative learning, or critical thinking, or its effect on composition quality, it examines students' responses on all three of these aspects. Additionally, the current study was carried out using five authentic writing and prewriting tasks. Furthermore, the results were broadly positive because reading comprehension and grammatical exercises were carried out alongside videos and subsequent debates and activities which stimulated improvements in learners' collaborative work, critical thinking and composition quality.

\section{Acknowledgments}

This project succeeded in reaching its final outcome thanks to the support, effort and assistance of a great many people and we feel extremely privileged to mention them upon the completion of this research.

We owe our deep gratitude to the Pontificia Universidad Católica del Ecuador, especially to its Investigation Department and its former director, Rommel Montúfar, who provided us with the opportunity to start and complete the project which lead to this article being published. We are extremely thankful to the same department's current director, Enrique Gea, for giving such kind support and guidance, despite his busy schedule.

We would also like to thank our students, who were participants in the project, although it would be difficult to name all of them.

We mustn't forget to acknowledge with great respect our editor Joanne Welling, and of course Narine Sargsyan, whose material formed the cornerstone of our project. Finally, of course, our research assistants, Estephany García and Edwin Montesdeoca, without whose help explaining the peer review tool would have been more difficult, as their background is closer to that of our students and they were able to lend a different perspective to this study. 


\section{References}

Baker, K. (2016). Peer Review as a Strategy for Improving Students' Writing Process. Active Learning in Higher Education, 1-14. https://doi.org/10.1177/1469787416654794

Birenbarum, M. (1996). Alternatives in Assessment of Achievement, Learning Processes and Prior Knowledge. Higher Education, 22, 17-30.

Boud, D., \& Molloy, E. (2013). Rethinking models of feedback for learning. In The challenge of design. Assessment \& Evaluation in Higher Education (pp. 698-712).

Cheng, P. (2009). Integrating Online Peer Reviews into a College Writing Class in Taiwan. PhD dissertations. Indiana University.

Coté, R. (2014). Peer Feedback in Anonymous Peer Review in an EFL Writing Class in Spain. Gist Education and Learning Research Journal, 9, 67-87.

Crossman, J., \& Kite, S. (2012). Facilitating Improved Writing among Students through Directed Peer Review. Higher Education Research and Development, 13(3), 219-229. https://doi.org/10.1177/1469787412452980

Deni, A. R., \& Zainal, I. Z. (2011). Peer-editing Practice in the Writing Classroom: Benefits and Drawbacks. Advances in Language and Literacy Studies, 2(1), 92-107. https://oi.org/10.7575/aiac.alls.v.2n.1p.92

Douchy, F., Segers, M., \& Sluijsmans, D. (1999). The Use of Self-, Peer and Coassessment in Higher Education: a Review. Studies in Higher Education, 24(3), 331-350. https://doi.org/10.1080/03075079912331379935

Evans, C. (2013). Making Sense of Assessment Feedback in Higher Education Review of Educational Research, $1,83,70-120$.

Fernández Dobao, A., \& Blum, A. (2012). Collaborative Writing Tasks in the L2 Classroom: Comparing Group, Pair, and Individual Work. Journal of Second Language Writing, 21, 40-58. https://doi.org/10.1016/j.jslw.2011.12.002

Gielen, M., \& De Wever, B. (2015). Structuring Peer Assessment: Comparing the Impact of the Degree of Structure on Peer Feedback Content. Computers in Human Behavior, 52, 315-325. https://doi.org/10.1016/j.chb.2015.06.019

Hammond, J., \& Macken-Horarik, M. (1999). Critical Literacy: Challenges and Questions for ESL Classrooms. TESOL Quarterly, 33(3), 528-544. https://doi.org/10.2307/3587678

Hanrahan, S., \& Isaacs, G. (2010). Assessing Self- and Peer-assessment: The Students' views. Higher Education Research and Development, 20(1), 53-70. https://doi.org/10.1080/07294360123776

Hodges, G. C. (2002). Learning through collaborative writing. Reading, 36, 4e10.

Hu, G. W. (2005). Using Peer Review with Chinese ESL Student Writers. Language Teaching Research, 9, 321-342. https://doi.org/10.1191/13621688051r169oa

Jacobs, E. (1981). Testing ESL Composition: a Practical Approach (1st ed.) Newbury House. Rowley: MA.

Jegerski, J., \& Ponti, E. (2014). Peer Review among Students of Spanish as a Heritage Language: the Effectiveness of a Metalinguistic Literacy Task. Linguistics and Education, 26, 70-82. https://doi.org/10.1016/j.linged.2014.03.002

Kim, S. (2015). Preparing English Learners for Effective Peer Review in the Writers' Workshop. The Reading Teacher, 68(8), 599-603. https://doi.org/10.1002/trtr.1358

Kuiken, F., \& Vedder, I. (2002b). Collaborative writing in L2: The effect of group interaction on text quality. In S. Ransdell, \& M. Barbier (Eds.), New directions for research in L2 writing (pp. 169-188). Dordrecht: Kluwer. Lantolf.

Martin, F., \& Provost, S. (2014). Teaching Students To Discriminate Between Good And Poor Writing. Procedia - Social and Behavioral Sciences, 141, 205-209. https://doi.org/10.1016/j.sbspro.2014.05.036

Neumann, H., \& McDonough, K. (2015). Exploring student interaction during collaborative prewriting discussions and its relationship to L2 writing. Journal of Second Language Writing, 27, 84-104. https://doi.org/10.1016/j.jslw.2014.09.009

Nicol, D., \& Macfarlane-Dick, D. (2006). Formative Assessment and Self - regulated Learning: a Model and Seven Principles of Good Feedback Practice. Studies in Higher Education, 31(2), 199-218. https://doi.org/10.1080/03075070600572090 
Pally, M. (1997). Critical Thinking in ESL: an Argument for Sustained Content. Journal of Second Language Writing, 6(3), 293-311. https://doi.org/10.1016/S1060-3743(97)90016-3

Planas Lladó, A., Soley, L. F., Fraguell Sansbelló, R. M., Pujolras, G. A., Planella, J. P., Roura-Pascual, N., \& Moreno, L. M. (2014). Student perceptions of peer assessment: an interdisciplinary study. Assessment \& Evaluation in Higher Education, 39(5), 592-610. http://doi.org/10.1080/02602938.2013.860077

Riazantseva, A. (2012). Outcome measure of L2 writing as a mediator of the effects of corrective feedback on students' ability to write accurately. Science Direct, 40, 421-430. https://doi.org/10.1016/j.system.2012.07.005

Shehadeh, A. (2011). Effects and Student Perceptions of Collaborative Writing in L2). Journal of Second Language Writing, 20, 286-305. https://doi.org/10.1016/j.jslw.2011.05.010

Storch, N. (2005). Collaborative writing: Product, process, and students' reflections. Journal of Second Language Writing, 14(3), 153-173. https://doi.org/10.1016/j.jslw.2005.05.002

Thomas, T. A. (2014). Developing team skills through a collaborative writing assignment. Assessment and Evaluation in Higher Education, 39(4), 479-495. https://doi.org/10.1111/j.1467-8535.2010.01059.x

Topping, K. (2009). Peer Assessment. Theory into Practice, 48(1), 20-27. https://doi.org/10.1080/00405840802577569

Vickerman, P. (2009). "Student Perpectives on Formative Peer-assessment: An Attempt to Deepen Learning?" Assessment \& Evaluation in Higher Education, 25, 149-170.

Vygotsky, L. S. (1978). Mind and society. Harvard University Press.

Wigglesworth, G., \& Storch, N. (2012). What role for collaboration in writing and writing feedback. Journal of Second Language Writing, 21, 364-374. https://doi.org/10.1016/j.jslw.2012.09.005

Yang, Y. (2011). A reciprocal peer review system to support college students' writing. British Journal of Educational Technology, 42(4), 687-700. https://doi.org/10.1111/j.1467-8535.2010.01059.x

Zare, P. (2015). Critical Thinking Skills among EFL/ESL Learners: a View of Literature. Language in India, 15(11), 241-257.

\section{Appendix}

\section{QUESTIONNAIRE}

The first questionnaire is about collaborative learning (CL) and includes the following statements:

(1). Planning outlines for our future writing assignments together helped me with the final outcome.

(2). I feel that my partner and I have a common goal, and together it is easier to reach it. (3). I feel that my contributions are helpful for my partners to improve their work.

(4). My partners' contributions were of great value in helping me produce a high-quality paper.

(5). I felt respected during the peer review process.

(6). I showed my partner respect.

(7). My partner and I could easily reach agreements.

(8). My partner helped me better understand the format and features of academic writing. (9). I would rather work in pairs or a group of three than alone.

(10). I enjoyed the peer review process.

The second questionnaire was linked to critical thinking (CT), and consisted of the points below:

(11). I was able to assess the strengths and weaknesses of my partner's paper.

(12). Through the process of peer review, I was able to re-evaluate my paper.

(13). I helped my partner to identify their writing obstacles and overcome them.

(14). I felt able to give and receive constructive feedback.

(15). My second draft provided evidence that I could approach the topic from different perspectives.

(16). I feel I understand what the peer review process is for. 
(17). I learnt from my partner's comments and suggestions on my essay.

(18). I analysed my own mistakes while reading and assessing my partner's essay.

(19). I could easily identify the purpose and the audience that the task required.

(20). I can differentiate appropriate academic writing from that which is not properly written.

The third questionnaire aimed to measure students' perceptions about the quality of their essay composition (CQ) having taken a course integrating the PR process. It included these questions:

(21). I was able to improve on aspects such as spelling and punctuation.

(22). I was able to improve on aspects such as grammar and structure.

(23). The content of my written production was relevant and appropriate for academic writing.

(24). The compositional organisation and format of my paper fulfilled the requirements of academic writing.

(25). The ideas I developed were interesting, authentic and engaging.

(26). My essay was cohesive. All the ideas were directly connected to the thesis statement.

(27). The language I used was varied and appropriate to the subject matter.

(28). I met my partner's and teacher's expectations in my final version.

(29). The peer review process has had a positive impact on my ability to write essays.

(30). My writing makes more sense now. I feel I am writing for a real audience and with a real purpose.

\section{Copyrights}

Copyright for this article is retained by the author(s), with first publication rights granted to the journal.

This is an open-access article distributed under the terms and conditions of the Creative Commons Attribution license (http://creativecommons.org/licenses/by/4.0/). 